\title{
Cold-Starting Abilities of Various Substitute Motor Fuels
}

\author{
By Ronald E. Streets
}

\begin{abstract}
Tests of various nonhydrocarbon fuels in a standard eight cylinder automotive engine showed the starting abilities of single constituent fuels to be rather limited, but the addition of small percentages of more volatile fuels lowered the minimum starting temperature to a marked degree.

A limited number of tests under altitude conditions also showed a further reduction in minimum starting temperature of each of the fuels used. This should compensate to some degree for the lower average temperatures generally encountered at higher altitudes, so that for any one area it would be possible to obtain satisfactory starting with a minimum amount of blend changes.
\end{abstract}

\section{Scope of Investigation}

At the request of the United States Foreign Economic Administration (originally the Board of Economic Warfare), the National Bureau of Standards undertook in 1942 an extensive investigation of substitute motor fuels to determine the technical feasibility of producing and using such fuels in foreign countries devoid of natural petroleum sources.

This report covers that phase of the work dealing with the minimum starting temperatures of the various fuels used and also to some extent the warming-up characteristics of those fuels. The majority of the test runs were made under atmospheric pressures approximately equivalent to sea level. However, in order to obtain some evaluation of the effect of large changes in atmospheric pressure, a limited number of runs were made under barometric pressures equivalent to altitudes of 5,000 and 10,000 feet.

\section{Fuels, Test Equipment, and Procedure}

The fuels used were the following: 200-proof ethyl alcohol, commercial grade; 190-proof ethyl alcohol, commercial grade; Diethyl ether, analytical grade; Acetone, analy tical grade; Isooctane, topped F-4 reference fuel; Saxet naphtha, ASTM distillation: $T_{10}=202^{\circ} \mathrm{F}, T_{50}=280^{\circ} \mathrm{F}, T_{90}=360^{\circ} \mathrm{F}$; Tailored gasoline, a blend of domestic aviation gasoline and a cleaning solvent. ASTM distillation: $T_{10}=178^{\circ} \mathrm{F}, T_{50}=268^{\circ} \mathrm{F}, T_{90}=353^{\circ} \mathrm{F}$.
The test engine was a reconditioned 1939 Ford $\mathrm{V}-8$, complete with generator, starter, and radiator. The unit was mounted on a suitable stand having an integral control panel containing the necessary switches, gages, and controls. The transmission and clutch were removed.

Measurements of cranking speed and time were made by means of a chronometric tachometer having a revolution counter synchronized through suitable switches with a timer reading to 0.001 minute.

Thermocouples were installed to measure the temperatures of cylinder metal, carburetor metal at the venturi and at the flange, carburetor intake air, and various points on the intake manifold. Glass thermometers were used for engine coolant temperature at the radiator top tank, crankcase oil temperature, carburetor metal at the venturi and ambient air temperature. Thermocouple temperatures were read at the engine with a Lewis potentiometer, which does not use a standard cell and is relatively unaffected by low temperatures.

The test method used was that outlined in "CFR Procedure for Testing the Starting and Warming-up Characteristics of Fuels," CRC designation F-6-943.

This procedure was used as outlined with the following exceptions: The battery temperature, voltage, and current consumption were not recorded; however, the specific gravity of the battery acid was maintained at 1.260 to 1.300 . The warmup speed selected was $1,000 \mathrm{rpm}$. 
Test fuels were supplied from auxiliary tanks placed at a level relatively the same as the vehicle fuel tank, with suitable valves for changing fuels during running.

The complete unit, including battery and all instruments, was placed in a refrigerated altitude chamber.

\section{Test Results}

\section{Starting at Sea Level}

Nearly 200 test runs were made with starting temperatures ranging from $-22^{\circ}$ to $+60^{\circ} \mathrm{F}$. For each of the fuels used, an attempt was made to obtain a curve of temperature versus cranking time for "first-fire."

First-fire denotes the first explosion and may be only a slight "kick" of the engine with very little noise, a smothered explosion, or a sharp exhaust noise.

The results of test runs on various fuels at sea level are plotted in figure 1. In general, the

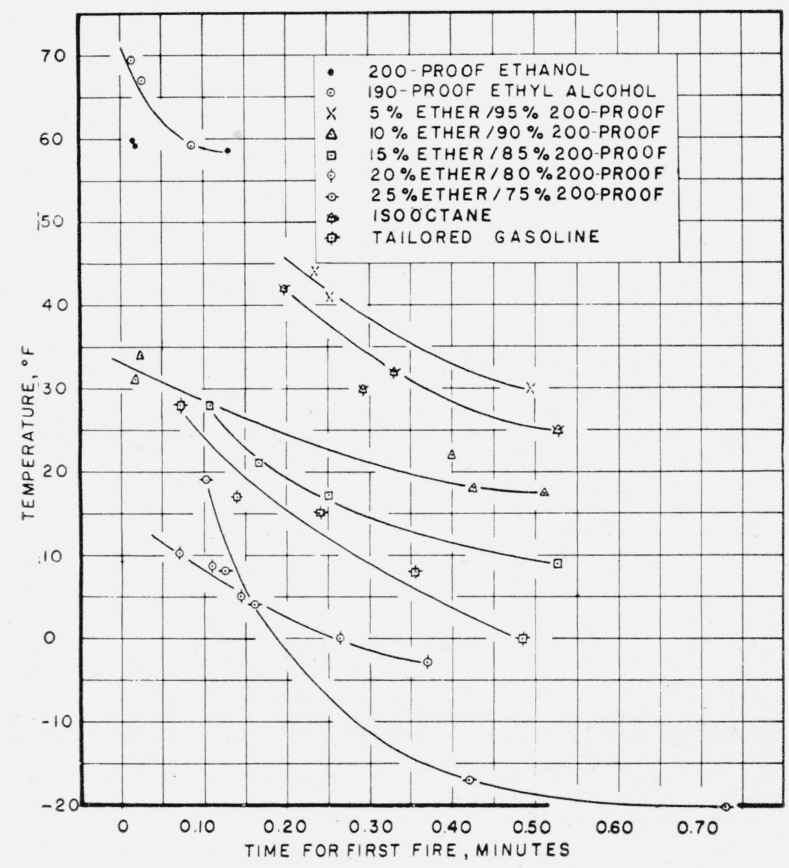

Figure 1.-Starting ranges of various fuels at sea level.

curves are similar for the several fuels used, although the 190- and 200-proof alcohols show a very marked cutoff point at about $59^{\circ} \mathrm{F}$. It was not found possible to lower this starting temperature even with long cranking time, for in each case this resulted in excessive condensation on the plug, causing misfire. From these curves it is apparent that small additions of more volatile components will greatly lower the minimum starting temperature: $42^{\circ} \mathrm{F}$ being obtained with a mixture of 5 percent of ether and 95 percent of 200-proof alcohol (by volume); $22.5^{\circ} \mathrm{F}$ with 10 percent of ether and 90 percent of 200 -proof alcohol; $16.5^{\circ} \mathrm{F}$ with 15 percent of ether and 85 percent of 200 proof alcohol; $0^{\circ} \mathrm{F}$ with 20 percent of ether and 80 percent of 200 -proof alcohol; and $-7^{\circ} \mathrm{F}$ with 25 percent of ether and 75 percent of 200 -proof alcohol, all values based on a cranking time of 0.250 minute. The fact that the curves for 20 percent of ether and 80 percent of 200-proof alcohol and 25 percent of ether and 75 percent of 200-proof alcohol cross each other may have been the result of blend changes during standing, as with high percentages of ether the mixtures have a tendency to weather badly at normal room temperature. The probable result would be to raise the starting temperature of blends containing large amounts of ether. For this reason, the curves for 20 percent of ether and 80 percent of 200-proof and 25 percent of ether and 75 percent of 200-proof alcohol may be somewhat doubtful, although they should represent the minimum lowering of starting temperature that could be obtained from these nominal blend concentrations, as any weathering would tend to increase the minimum starting temperature.

To facilitate estimation of probable starting temperatures, and also to show more clearly the effect of ether additions to alcohol, figure 2 has been prepared. In this, the interpolations from figure 1 are shown as two curves, one based on a cranking time for first-fire of 0.250 minute, the other based on no time limit or, in other words, the lowest temperature at which a first-fire could be detected with this particular test setup.

The lowest temperature at which a start may be obtained will vary for each fuel with respect to cranking time, hence it seems desirable to specify some maximum time limit for cranking. Experience has shown that, in general, unless a start is obtained in 20 seconds, further cranking is not worthwhile, as condensation on the spark-plug porcelain and points will effectively short-circuit the ignition. For this reason, 15 seconds, or 0.250 minute, was selected as a desirable maximum cranking time within which a start should be made. Thus, although the curve for no time limit is shown 
in figure 2 , it must be emphasized that a start at these temperatures is based on controlled laboratory conditions with a well-maintained engine and should not be expected in the usual vehicle. The curves in figure 2 are believed accurate within \pm 2 deg $\mathrm{F}$ for purposes of predicting blend requirements or starting abilities of given blends.

In figure 3 are presented the starting-range

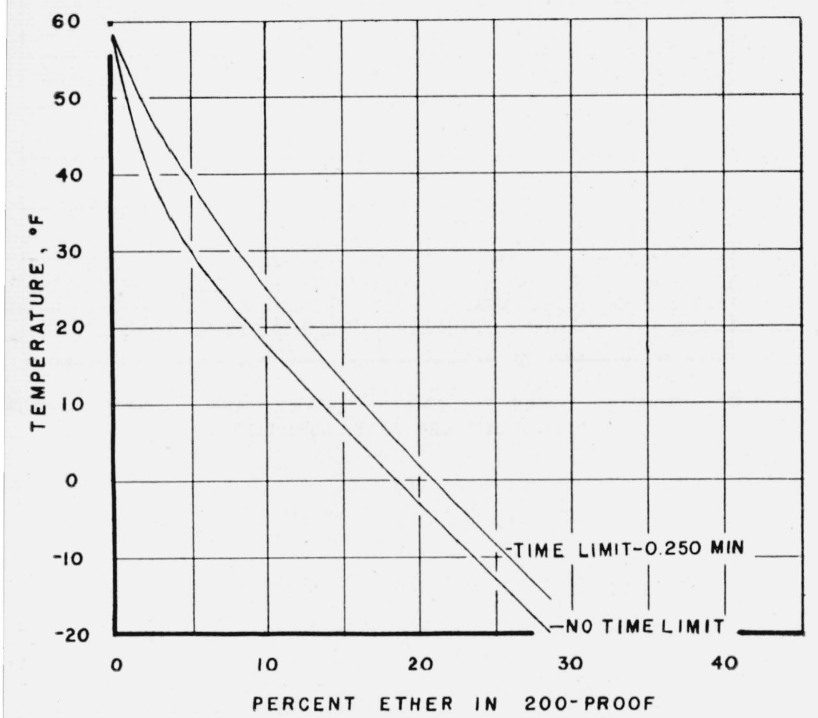

FIGURE 2.-Minimum starting temperatures of ether-200proof alcohol blends at sea level.

The values for the blends used were interpolated from the starting range curves in figure 1.

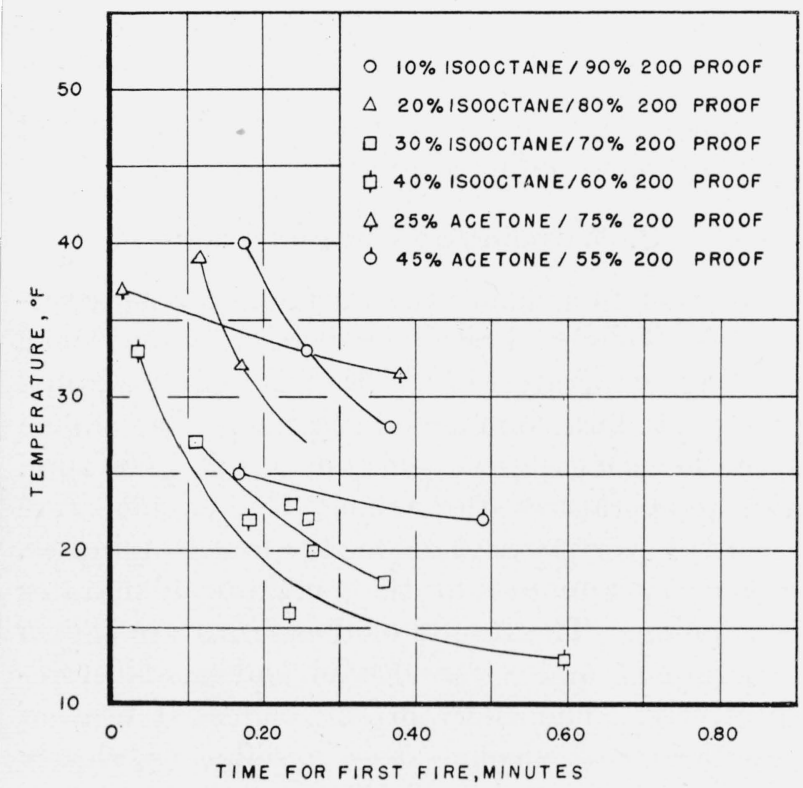

FIGURE 3.-Starting ranges of isooctane-200-proof alcohol and acetone-200-proof-alcohol blends at sea level. curves of blends of isooctane and 200-proof and two blends of acetone and 200-proof alcohol. In figure 4 the results of tests on blends of Saxet naphtha and 200-proof alcohol are shown.

In order to present these latter data in more usable form, the curves in figure 5 have been produced by interpolation of the probable minimum starting temperature of each blend, based on a

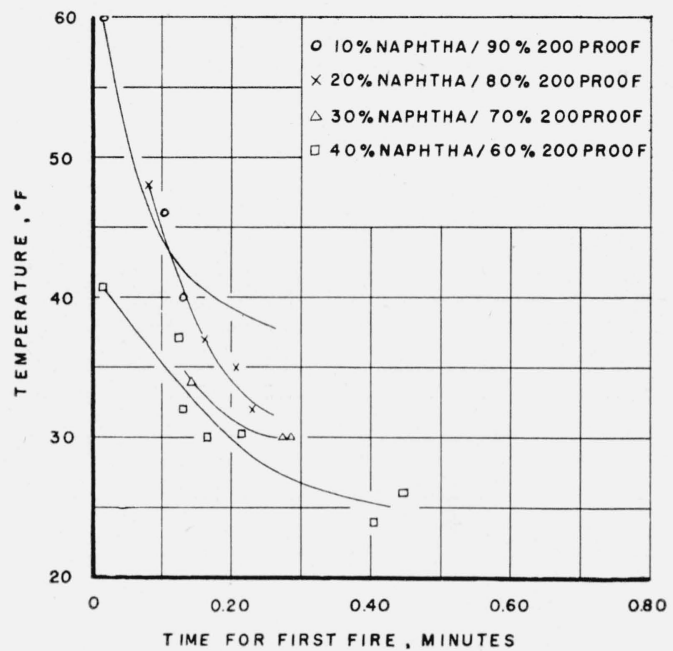

FIGURE 4.-Starting ranges of Saxet naphtha-200-proofalcohol blends at sea level.

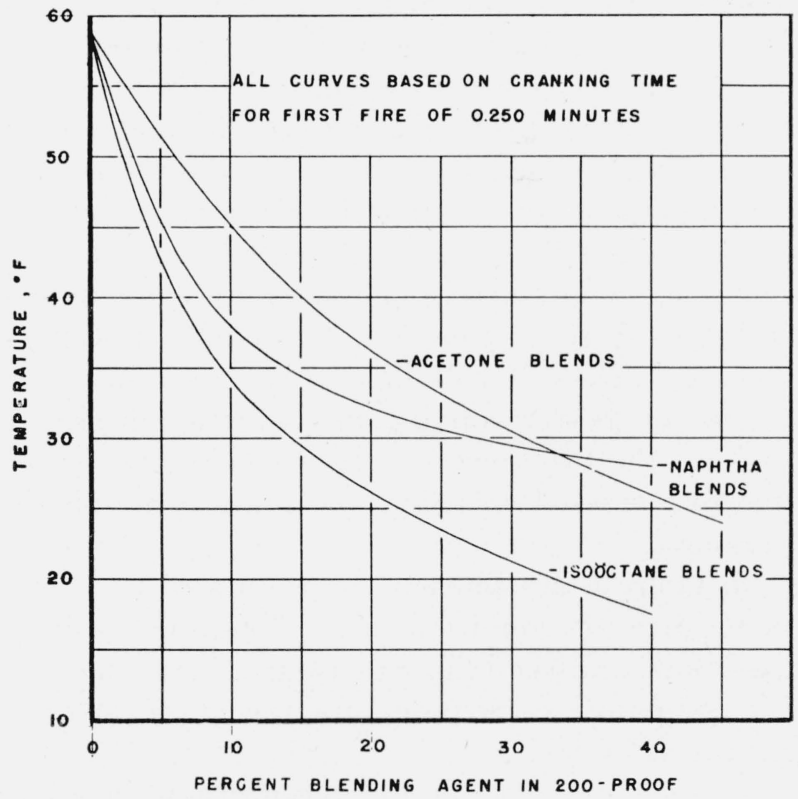

Figure 5.-Minimum starting temperatures of acetone-200proof, isooctane-200-proof, and naphtha-200-proof alcohol blends at sea level.

The values for the blends used were interpolated from the starting range curves in figures 3 and 4 . 
cranking time for first-fire of 0.250 minute. Figure 5 shows rather clearly the large decrease in starting temperature produced by the addition of small percentages of more volatile fuel. By comparison with figure 2 , the relative influence of various additives in alcohol may be seen. In table 1 are tabulated these decreases in minimum starting temperature for various amounts of each additive.

TABLE 1.-Lowering of minimum starting temperature of 200-proof ethyl alcohol, ${ }^{\circ} \mathrm{F}$, based on cranking time for first-fire of 0.250 minute

\begin{tabular}{|c|c|c|c|c|c|}
\hline \multirow{2}{*}{ Blending agent } & \multicolumn{5}{|c|}{ Volume percent added } \\
\hline & 5 & 10 & 15 & 20 & 25 \\
\hline & ${ }^{\circ} \mathrm{F}$ & ${ }^{\circ} \mathrm{F}$ & ${ }^{\circ} \mathrm{F}$ & ${ }^{\circ} \mathrm{F}$ & ${ }^{\circ} \mathrm{F}$ \\
\hline Diethyl ether. & 20 & 34 & 46 & 57 & 67.5 \\
\hline Isooctane & 16.5 & 25 & 29.5 & 33 & 35.5 \\
\hline Saxet Naphtha & 13.5 & 21 & 24.5 & 27 & 28.5 \\
\hline Acetone & 7.5 & 14 & 19 & 23 & 26 \\
\hline
\end{tabular}

\section{Starting at Altitude}

A limited number of test runs were made under altitude conditions of 5,000 and 10,000 ft in order to determine the possible decrease in minimum starting temperature that might be expected because of decrease in barometric pressure. It was observed that, although the ambient air temperature decreases with altitude, the corresponding decrease in atmospheric pressure might compensate to some degree by increasing the effective vapor pressure of the fuel. This would be desirable from the standpoint of the individuals concerned with fuel blending to cover an expected temperature range, as good starting characteristics are necessarily obtained at some loss of resistance to vaporlocking. Thus, if volatility is increased in order to provide better starting in cooler mountainous regions, the tendency to vapor-lock is increased, due to increased volatility and lower atmospheric pressure.

In figure 6 are plotted the results of test runs under altitude conditions using 200-proof alcohol, isooctane, and the tailored gasoline. Also plotted for comparative purposes are the sea-level data for the same fuels.

As seen from the figure, the decrease in mini mum starting temperature due to altitude is quite large. The values for sea level and for altitude for each fuel are tabulated in table 2 , all based on a time for first-fire of 0.250 minute. The values

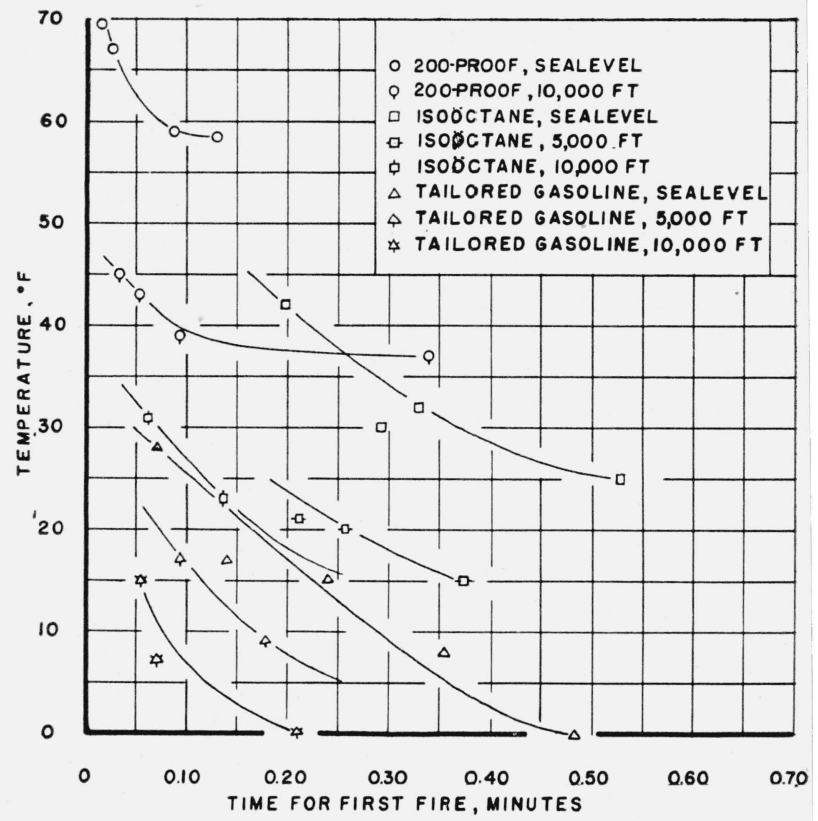

FIGURE 6.-Comparison of starting ranges of various fuels at sea level and at altitude.

TABLE 2.-Temperature lowering at altitude

\begin{tabular}{|c|c|c|c|c|c|}
\hline \multirow{2}{*}{ Fuel } & \multicolumn{3}{|c|}{$\begin{array}{c}\text { Starting temperature } \\
\text { at- }\end{array}$} & \multicolumn{2}{|c|}{$\begin{array}{l}\text { Temperature } \\
\text { lowering at- }\end{array}$} \\
\hline & $\begin{array}{c}\text { Sea } \\
\text { level }\end{array}$ & $\underset{\mathrm{ft}}{5,000}$ & $\begin{array}{c}10,000 \\
\mathrm{ft}\end{array}$ & $\begin{array}{c}5,000 \\
\mathrm{ft}\end{array}$ & $\begin{array}{c}10,000 \\
\mathrm{ft}\end{array}$ \\
\hline & $\circ F$ & ${ }^{\circ} F$ & $\circ F$ & ${ }^{\circ} F$ & ${ }^{\circ} F$ \\
\hline 200-proof ethyl alcohol. & 59 & 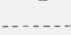 & 37 & $\ldots$ & 22 \\
\hline Isooctane & 37.5 & 20.5 & 15.5 & 17 & 22 \\
\hline Tailored gasoline...... & 13 & 5.5 & -1.5 & 7.5 & 14.5 \\
\hline
\end{tabular}

for tailored gasoline at altitude, and isooctane at $10,000 \mathrm{ft}$ were obtained by extrapolation.

\section{Warming-up Characteristics}

In order to compare the warming-up characteristics of alcohol and gasoline, runs were made from a starting temperature of $60^{\circ} \mathrm{F}$ on 200-proof alcohol and a standard commercial gasoline. The engine speed in each case was held constant at 1,000 rpm, and temperatures throughout the engine were recorded every 30 seconds for the first 10 minutes, then every 5 minutes for the remaining 40 minutes of running. The results of these runs are shown in figures 7 and 8 for alcohol and gasoline, respectively. The effect of the increased heat of vaporation of alcohol over gasoline is clearly shown in figure 9 , in which the relative temperatures during operation on alcohol are compared 
with those obtained during the gasoline run as a datum level. This increased cooling with alcohol is also made larger by the fact that approximately $1 \frac{1}{2}$ times as much alcohol is required to produce the same power as a given weight of gasoline, due to the lower heat of combustion. Hence the total cooling effect is approximately 5 times as great for alcohol as for gasoline during comparable operation $[1] .^{1}$

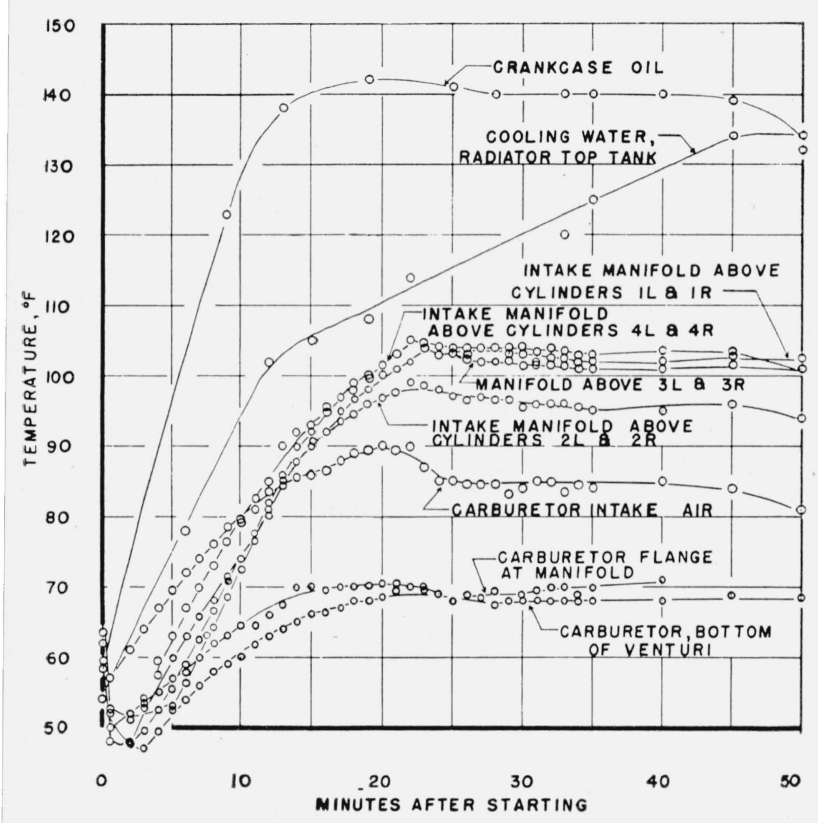

FIGURE 7.-Warming-up characteristics during operation with 200-proof alcohol.
Although the charge density and hence, power, would be increased by lower manifold temperatures, distribution would undoubtedly be poorer and thermal efficiency should be lowered. In addition, starts near the minimum starting tempera-

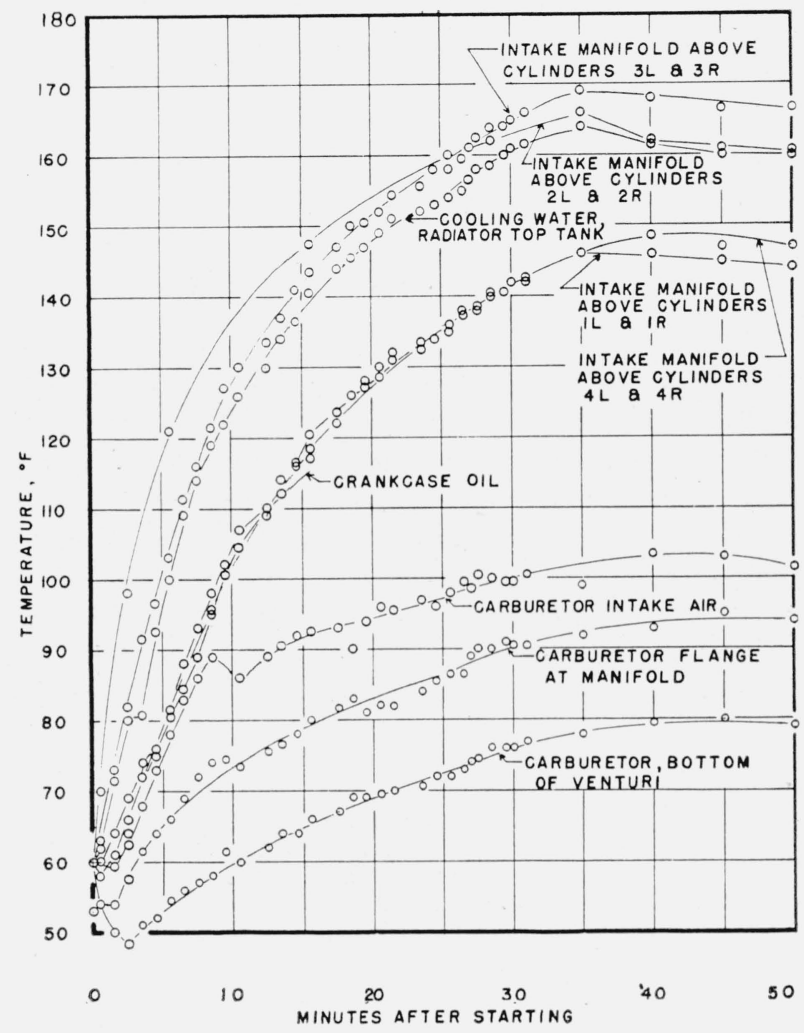

FIGURE 8.-Warming-up characteristics during operation with gasoline.

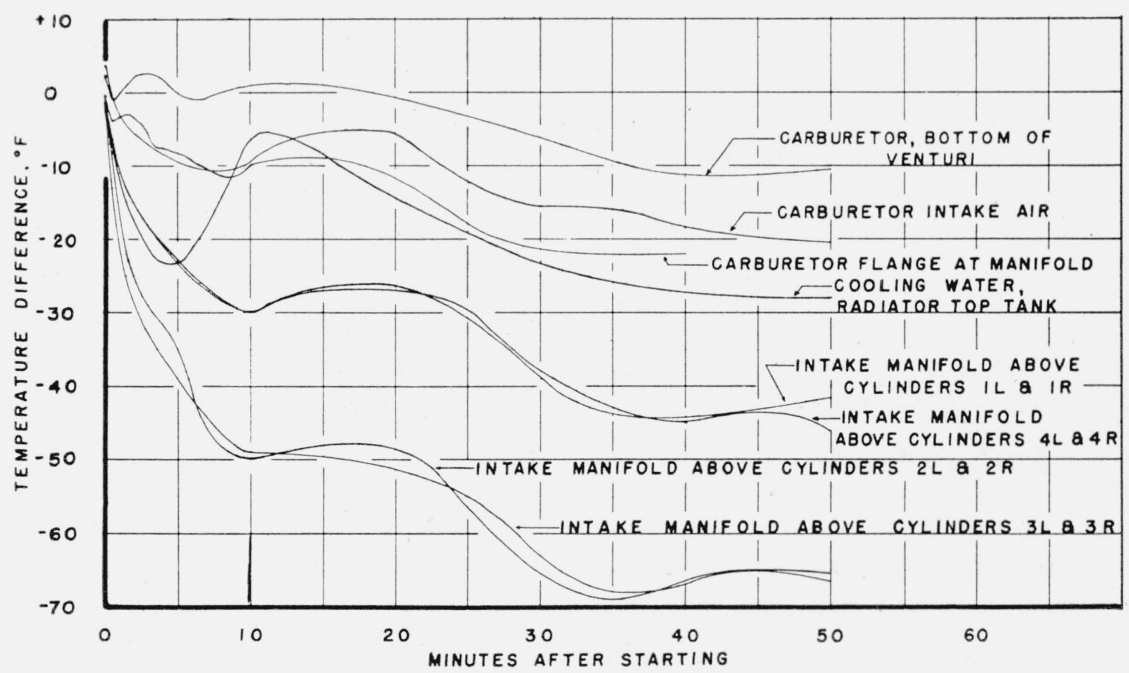

FIGURE 9.-Relative warming-up temperatures of alcohol and gasoline.

The curves plotted represent temperatures during alcohol operation minus temperatures during gasoline operation.

${ }_{1}^{1}$ Figures in brackets indicate the literature references at the end of this paper. 
ture result in excessive warming-up time and greater oil dilution. It was observed in some tests close to the minimum starting temperature, that the cooling of the charge just following a start would reduce vaporization, resulting in too lean a mixture being inducted into the cylinder, following which the engine would cease firing unless precautions were taken to increase the supplied fuel-air ratio.

The additional amount of heat that must be supplied in order to provide 100 percent evaporation could be computed for each speed and load, based upon the specific fuel consumption, and this in turn might be used as a basis for redesigning the manifolding in order to provide additional exhaust heat transfer through hot-spots or to increase the amount of exhaust bypass through the intake manifold riser. In all probability, it would be desirable to combine both methods so that deficiencies in distribution might be corrected. The necessity for this change with alcohol operation has been shown by Duck and Bruce [2].

It should be mentioned that standard carburetor jets and nozzles were used for all runs on isoöctane, standard gasoline, and tailored gasoline. For all runs with ethyl alcohol, neat and blended, jets, nozzles, and passages were altered in accordance with previous determinations of the required changes for proper operation with ethyl alcohol [2]. It is reasonable to assume that the warming-up characteristics of alcohol blends will differ somewhat from that of 200-proof as there will be changes in the heat of vaporization. In addition, with large percentages of hydrocarbon addition to alcohol, the jets and passages should be reduced in size corresponding to the increase in heat of combustion of the blend with increase in additive. This will tend to increase warming-up temperatures due to smaller volume of fuel being handled.

\section{Discussion}

\section{Starting at Sea Level}

(a) Desirability of Various Blending Agents

From a study of figures 1 to 5 , it is apparent that ether provides an additive more suitable for lowering the minimum starting temperature of alcohol than any of the several fuels used. The following advantages may be shown: (1) Per unit volume, ether is most effective in lowering the minimum starting temperature, (2) from the standpoint of water tolerance, ether-alcohol blends will not separate as will isooctane and petroleum naphtha blends with alcohol. Acetone-alcohol blends are also satisfactory in this respect, (3) in considering the use of substitute fuels, it should be remembered that both ether and acetone could be easily produced in conjunction with alcohol production. As the reason for the use of alcohol would be largely the lack of petroleum sources, it would be both costly and unwise to use a hydrocarbon additive for increased volatility, (4) although acetone meets with the requirements for water tolerance and ease of production, excessively large volumes are required to provide the same starting ability as ether. (45\% acetone is required to produce same starting ability as $10 \%$ ether.)

The greatest disadvantage in using ether is in its handling, for its high volatility, low flash point, and wide inflammability limits make it a very hazardous fuel. However, this applies in a general way to all low-boiling fuels, and if proper safeguards are taken the hazard need be no greater than that of handling other fuels. In view of the above, ether-alcohol blends have been selected as the most practical.

\section{(b) Theoretical Considerations}

In figure 10 the experimental minimum starting temperatures of 200-proof ethyl alcohol, isooctane, tailored gasoline, and blends of ether-alcohol are plotted along with the calculated theoretical values. The experimental values for ether-alcohol blends were obtained by interpolation from the smoothed curve in figure 2. For the fuels other than tailored gasoline, the required vapor pressures were computed from the following:

$$
\frac{P_{v}}{P_{B}-P_{m}}=x \text {. }
$$

where $P_{v}=$ required vapor pressure for formation of an explosive mixture, $\mathrm{mm} \mathrm{Hg}$ $P_{B}=$ barometric pressure, $\mathrm{mm} \mathrm{Hg}$ (for sea-level conditions the standard pressure of 760 was assumed; for $5,000 \mathrm{ft}, 632 \mathrm{~mm}$ was used, and for $10,000 \mathrm{ft}$ the assumed pressure was $523 \mathrm{~mm}$ )

$P_{m}=$ intake manifold suction, $\mathrm{mm} \mathrm{Hg}$ $x=$ minimum inflammability limit, percentage by volume of vapor in air. 


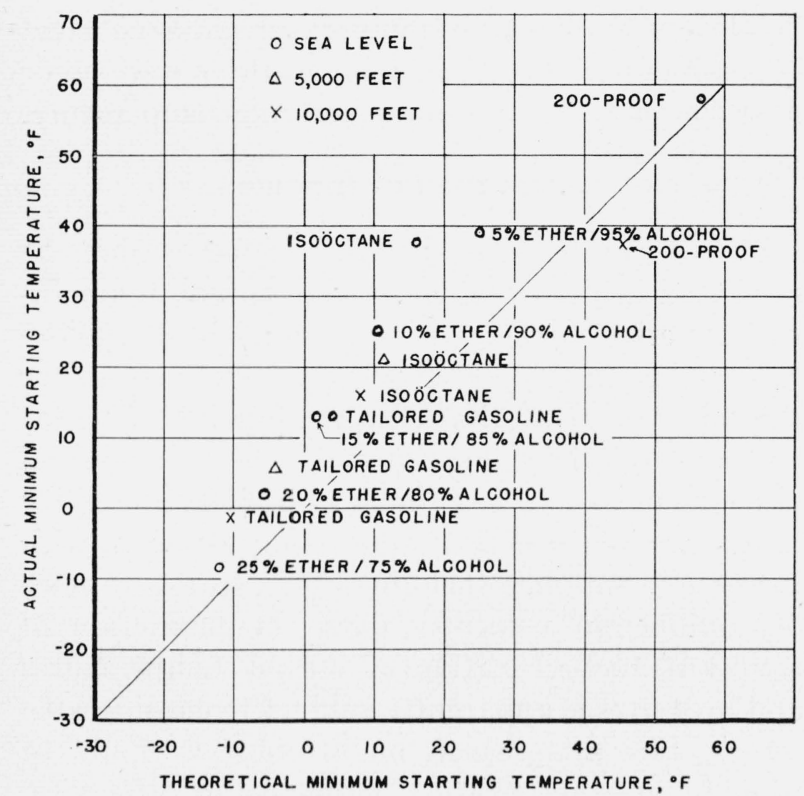

Figure 10.-Comparison of actual and theoretical minimum starting temperatures of various fuels at sea level and at altitude.

All experimental values are based on a time limit for first fire of 0.250 minute.

The temperature at which an ignitable mixture was formed was estimated from the vapor-pressure curve of each fuel. For ether and alcohol the minimum inflammability limits were obtained from International Critical tables.

For the ether-alcohol blends, the minimum inflammability limit was assumed to be that of ether, as the amount of less volatile component would be small at these temperatures.

The minimum starting temperatures of pure compounds can be estimated rather closely from vapor pressure data and minimum inflammability limits. With small percentages of vapor in air and at low pressures, the vapor may be treated as a gas and the required partial pressure can be computed using Dalton's Law of Partial Pressures. From this the temperature can be obtained by reference to vapor-pressure data.

In the case of blended fuels, a more satisfactory method is correlation with equilibrium air distillation data. For gasoline with normal distillation curves, this correlation can be obtained from ASTM distillation data by the method outlined by Bridgeman [3]. In these tests the theoretical minimum starting temperature of the tailored gasoline was estimated from ASTM distillation data, using an equilibrium air distillation chart prepared by the Standard Oil Co. of California from National Bureau of Standards data.

For other types of fuel blends, equilibrium air distillation data are not available. Therefore, the theoretical values for ether-alcohol blends were estimated by a method similar to that for pure compounds. Vapor pressure data for these blends were obtained from the work of Louder et al [4]. The method for pure compounds and binary blends introduces obvious errors as it assumes that equilibrium air-vapor mixtures are inducted into the cylinder. In the actual engine this may not be true, as the relatively short time lapse during which the supplied mixture travels from the carburetor to the cylinder may preclude the possibility of sufficient heat transfer to form an equilibrium mixture. Further, as cranking continues, the temperatures of carburetor and manifold are lowered, causing additional vapor to condense, thus reducing the resultant fuel-air ratio.

In many cases only meager data on vapor pressure are available in the literature. Where possible, it is advisable to utilize experimental data in determining the temperature necessary for formation of a minimum explosive fuel-air mixture. For pure compounds and some binary mixtures such data are available in the literature. However, for many mixtures the deviations from Raoult's law are too large to allow accurate vapor pressure calculations.

In order to provide a simple and fairly accurate method of determining the vapor pressure curves of such mixtures, resort may be had to the Clapeyron equation, which expresses quantitatively the variation of vapor pressure with temperature:

$$
\frac{d P}{d T}=\frac{L}{T \Delta v}
$$

where

$T=$ absolute temperature

$L=$ molal latent heat of vaporization

$\Delta v=$ volume of a mole of vapor minus that of a mole of liquid at temperature $T$ $P=$ vapor pressure.

Assuming that the volume of liquid is negligible compared with the volume of vapor, and that at low pressures the vapor behaves according to the 
ideal gas laws, we can substitute for $P v=R T$, or $1 / v=P / R T$. Therefore, eq 1 becomes

$$
\frac{d P}{d T}=\frac{L P}{R T^{2}}
$$

or

$$
\frac{d P}{P}=\frac{(L)}{(R)} \frac{(d T)}{\left(T^{2}\right)}
$$

On integrating, assuming $L$ is constant, we have

$$
\ln P=\frac{-(L)}{(R T)}+C
$$

These assumptions indicate that the Jogarithm of vapor pressure is linear with respect to the reciprocal of absolute temperature, which is the basis for several vapor pressure vs temperature charts. Thus a curve on such a chart can be obtained by knowing only two points, such as the boiling points at two pressures.

Various modifications of this method have been proposed, such as the Cox chart [5], and the method of Othmer [6]. A further relationship that has been found useful is Duhring's rule, which states that the temperature at which one liquid exerts a given vapor pressure is a linear function of the temperature at which a second liquid exerts the same vapor pressure. This rule holds more closely the greater the chemical and physical similarity between the two liquids.

Although the points plotted in figure 10 show a considerable variance between actual and theoretical values, it should be remembered that the experimental values are based on a time limit of 0.250 minute for first-fire as a criterion. In theory it might be assumed that with infinite cranking time the experimental values would closely approach the theoretical values. In the actual engine this is not possible because of certain limiting conditions: a, Condensation on the spark plug electrodes and porcelain will prevent firing even though a combustible mixture is attained; b, excessive cranking will cause rapid oil dilution and loss of compression. (In many cases this effect was evidenced by a distinctly audible piston "squeak" as continued cranking caused the oil to be washed off the cylinder walls.); $\mathrm{c}$, the temperatures of carburetor and manifold are rapidly reduced as heat is supplied to vaporize the fuel. This soon results in engine temperatures considera- bly below ambient air temperature and no start is possible if the original temperatures were at or near the probable minimum starting temperature.

\section{Starting at Altitude}

The effect of altitude on starting cannot be predicted with certainty. The actual temperature lowering in each case was more than could be expected from calculated values. The reasons for this are not clear from the standpoint of vapor pressure relations but may be due to several phenomena such as change in inflammability limits or increase in vapor concentration with increase in supplied fuel-air ratio. In the absence of equilibrium volatility data the prediction of resultant fuel-air ratios at stated temperatures and pressures is apparently subject to considerable error. For this reason no attempt is made to provide an exact relation, empirical or otherwise, for the estimation of minimum starting temperatures of any of the fuels covered in these tests. The line in figure 10 is drawn merely to show the deviations of the actual over theoretical values, as it represents the ideal correlation where actual and theoretical values coincide.

\section{Conclusions}

From the standpoint of starting, operation on ethyl alcohol is possible over wide temperature ranges by the use of small precentages of more volatile additives. The most effective and most desirable additive appears to be diethyl ether although there are many other additives, both hydrocarbon and nonhydrocarbon, that may be used.

Although a rough estimate of starting ability may be made from vapor pressure and inflammability limit data, it would be desirable to conduct actual test runs where fuels or blends not already investigated are to be used. It is felt that more information on equilibrium volatility of blends other than gasoline would provide closer estimation of minimum starting temperatures than is possible at present.

Warming-up with ethyl alcohol and its blends is much slower and does not produce temperatures high enough for good distribution and complete vaporization. If possible, the heat transfer from exhaust to intake manifold should be increased 
TABLE 3.-Suitable alcohol blends for starting

\begin{tabular}{|c|c|}
\hline Temperature & Additive in alcohol, percent by volume of- \\
\hline $\begin{array}{l}{ }^{\circ} F \\
50 \\
40 \\
30 \\
20 \\
10 \\
0\end{array}$ & $\begin{array}{l}2 \% \text { ether; } 6 \% \text { acetone; } 2.3 \% \text { isooctane. } \\
4.7 \% \text { ether; } 15 \% \text { acetone; } 6.2 \% \text { isooctane. } \\
8 \% \text { ether; } 31 \% \text { acetone; } 14.3 \% \text { isooctane. } \\
12 \% \text { ether; } 33 \% \text { isooctane. } \\
16.3 \% \text { ether. } \\
21 \% \text { ether. } \\
25.7 \% \text { ether. } \\
31 \% \text { ether. }\end{array}$ \\
\hline
\end{tabular}

where best operation on ethyl alcohol and its blends is desired.

The effect of altitude conditions in lowering minimum starting temperatures is quite pronounced and should compensate partially for the lower average temperatures encountered in moun- tainous regions, thus reducing blend requirements to a minimum.

Table 3 has been prepared to show the blends necessary to provide adequate starting at various temperatures at sea level.

\section{References}

[1] D. B. Brooks, NBS J. Research 35, 1 (1945) RP1660.

[2] J. T. Duck and C. S. Bruce, NBS J. Research 35, 462 (1945) RP1681.

[3] O. C. Bridgeman, J. Research NBS 13, 81 (1934) RP694.

[4] E. A. Louder, T. R. Briggs, and A. W. Browne, Ind. Eng. Chem. 16, 932 (1924).

[5] E. R. Cox, Ind. Eng. Chem. 15, 592 (1923).

[6] D. F. Othmer, Ind. Eng. Chem. 32, 841 (1940).

Washington, July 25, 1946. 